\title{
Job Prospects of Different EMI Engineering Programmes' Graduates
}

\author{
Mehmet Altay \\ Department of Foreign Language Education, Kocaeli University, Kocaeli, Turkey \\ ORCID: 0000-0001-7227-5685
}

Doğan Yüksel *

Department of Foreign Language Education, Kocaeli University, Kocaeli, Turkey ORCID: 0000-0001-9131-3907

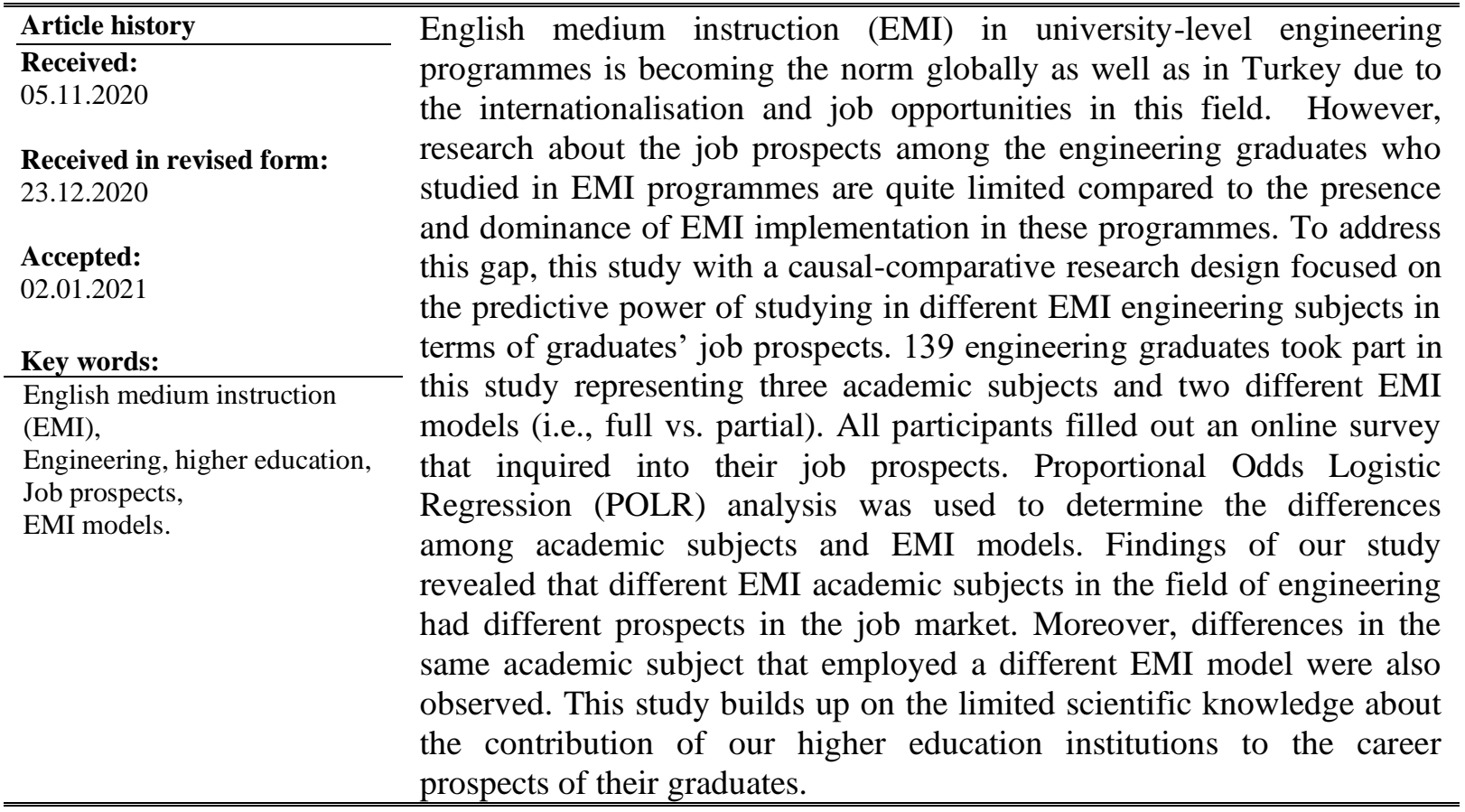

\section{Introduction}

English Medium Instruction (EMI), which entails "the use of the English language to teach academic subjects (other than English itself) in countries or jurisdictions where the first language (L1) of the majority of the population is not English" (Macaro, 2018; p. 18), has become a pervasive trend in many higher education (HE) settings all around the world such as Japan (Galloway, Kriukow, \& Numajiri, 2017) China (Fang, 2018), Europe (Wächter \& Maiworm, 2014) as well as Turkey (Curle, Yuksel, Soruç, \& Altay, 2020). To put simply, EMI refers to the teaching of a subject (e.g., Economics, Engineering, Medicine, etc.) in English with the motivation of reaching international students or increasing the prestige of the programmes or universities, among other factors.

\footnotetext{
*Correspondency: doganyuksel@gmail.com
} 
Some previous studies focused on the reasons for the boom of EMI programmes in various HE settings globally. The most oft-cited reason regards EMI as a part of the popular trend of internationalisation (e.g., O'Dowd, 2015). Other reasons include the demand to reach more domestic and international students (e.g., Dafouz, 2018; Doiz, Lasagabaster \& Sierra, 2013), expanding the prestige of educational programs (e.g., Nguyen, Walkinshaw \& Pham, 2017), and attaining a reputable status in the international market (e.g., Graddol, 2006). Another commonly articulated reason is attaining better job prospects after graduation (e.g., Huang, 2011), which is the focus of this study. Building on the current research that examines the interplay between EMI and jobs prospects (Altay, 2020; Altay \& Ercin, 2020), this study investigates the impact of EMI studies on the graduates' job prospects by comparing different academic subjects and full (i.e., 100\%) and partial (i.e., 30\%) EMI models as defined by Macaro (2018).

\section{Review of Literature}

\section{EMI in Turkey}

Early studies in the Turkish EMI context have focused on the perceptions of EMI teachers (e.g., Sert, 2008) and students (e.g., Kırkgöz, 2014) towards the place and significance of EMI studies and their motivations to pursue EMI degrees (e.g., Kırkgöz, 2005). However, a recent trend of studies has examined the reasons of academic success (e.g., Altay, Soruc, Yuksel \& Curle, under review; Curle et al, 2020) and language related academic challenges students encounter during their EMI studies (e.g., Soruç \& Griffiths, 2018; Soruç, Dinler, \& Griffiths, 2018). Another strong trend has been the issue of job prospects after graduating from EMI programmes (e.g., Altay, 2020; Altay \& Ercin, 2020).

\section{How EMI Contributes to Work Life After Graduation}

Many HE institutions all around the world opt for programmes instructed in English to increase the student and teaching mobility and to increase their students' career prospects (Björkman 2008; Irvine, Pecorari, Shaw \& Malmström, 2011; Zhang 2017). In the Turkish setting, some previous studies on this topic reported that the beliefs and perceptions of the students concurred with this implication that EMI facilitates the attainment of better occupation opportunities (Kurkgöz, 2005; Oz, 2005). Similar beliefs and assumptions were also reported in some other settings such as China (Zhang 2017). However, not many studies followed up with the students after graduation and inquired into their career prospects and opportunities after they finish their EMI studies.

Moreover, there were some studies that reported more doubtful implications in terms of the perceptions of the students. Specifically, some students in the Chinese setting argued that career opportunities after studying in EMI programmes might not be open for all students and only a privileged group of students benefitted from EMI studies ( $\mathrm{Hu}, \mathrm{Li}, \& \mathrm{Lei}, 2014)$. That said, the place of English in the job setting was not prevalent and many EMI graduates did not use English in the job settings (Yang 2006; Gil 2010). These contradictory findings in the perceptions and beliefs of students and the initial assumptions about implementing EMI programmes globally call for further research on this topic.

To address this gap in the literature partially, in a series of studies Altay and his colleagues (Altay, 2020; Altay \& Ercin, 2020) examined how EMI impacted students' careers after graduation in various engineering academic subjects to illustrate the differences in different 
academic subjects as well as different implementation models of EMI. However, to our best knowledge, no prior study has focused on the differences in various academic subjects in the engineering programmes. Building up on these previous studies and addressing the gap in the literature, this study focuses on the following research question:

1- Does studying in a different EMI engineering subject help predict graduates' job prospects in terms of:
(a) the employment status,
(b) income,
(c) working in a division-related job,
(d) working in a subject-related job, and
(e) duration of seeking a job?

\section{Methodology}

\section{Context of the study}

Unlike most other EMI contexts, Turkey is not an ex-colonized country with a relatively long history of EMI. The number of HE programmes which adopt English as the medium of instruction has tended to grow even exponentially after the 2008 Regulations of Education in a Foreign Language by the Council of Higher Education. The programmes with this respect offer their students either full-EMI or partial-EMI studies. The latter, also known as 'Multilingual Model' (Macaro, 2018), requires at least two courses in EMI per semester and this accounts for a minimum of $30 \%$ of the courses. The data of this current study came from two state universities- from each EMI type. Both universities were located in industrial zones of the country and thus come into prominence with their engineering faculties. The total student population was approximately 50,000 students in each.

\section{Participants}

The number of academic programmes at the full-EMI engineering division was nine while it was six at the partial-EMI. Only four of these academic programmes were the same at both universities; however, the sample size of one of these programmes far outweighed and thus it was excluded from the dataset. The remaining three academic programmes that had been explored in this study were: (1) civil engineering, (2) electrical engineering, and (3) mechanical engineering. Stratified sampling was applied to make a subject-wise comparison possible. The distribution of the participants into subjects is as given in Table 1:

Table 1. Distribution of the Samples into EMI Subjects

\begin{tabular}{lllll}
\hline $\begin{array}{l}\text { EMI } \\
\text { type }\end{array}$ & Total Participants & Civil Engineering & Electrical Engineering & Mechanical Engineering \\
\hline Full & 71 & 20 & 22 & 27 \\
Partial & 68 & 20 & 22 & 26 \\
\hline
\end{tabular}




\section{Research design}

This work takes the form of a causal-comparative research design of the EMI graduates' job prospects. Quantitative modes of enquiry were employed to provide insight into the comparison of different EMI types and subjects. The findings from the statistical comparison were analysed and the probable causes of them were discussed through putting these variations into the perspective.

\section{Data collection}

The study was conducted in the form of a survey (see Appendix) developed by the authors, with data gathered via an online survey on participants' consent. In addition to two demographic questions aiming to cluster participants into their universities and subjects, five research items were directed to investigate: \#1 the employment status, \#2 monthly income, \#3 working in a job related to their academic division, \#4 working in a job related to their academic subject, and \#5 the duration of being employed. The validity of the items was checked through feedback from two experts in EMI (Dörnyei, 2007) before conducting the survey.

\section{Data analysis}

The collected data were statistically analysed through using the computing software R. Items \#1, \#3, and \#4 were nominal-scaled while items \#2 and \#5 were ordinal-scaled. Therefore, all dependent variables were categorical. Since the factor variable was the subjects of the participants and it was also categorical, all variable outcomes were transformed into dichotomous outcomes. Then Proportional Odds Logistic Regression Analysis was formulated in each analysis. The distribution of the participants preceded the analyses in contingency tables and Fitted Line Plots were obtained from Minitab Statistical Software to illustrate the regressions. Nagelkerke $\mathrm{R}^{2}$ was used as the index to refer to the variation in the coefficient of determination in all five analyses (Peng, Lee \& Ingersoll, 2002). Cohen's (1988) standardized mean difference statistic were used in the interpretation of the effect sizes.

\section{Results}

\section{The Employment Status}

The first survey item aimed to investigate whether the EMI subject types of the participants predict their employment status. The options were three-fold as: "working"; "not working, actively seeking new opportunities"; and "not working, not seeking opportunities". Working included both full time and part-time positions. Table 2 of crosstabulation indicates the distribution of the participants: 
Table 2. Crosstabulation of the Employment Status upon EMI Subject Types

\begin{tabular}{|c|c|c|c|c|c|c|c|}
\hline $\begin{array}{l}\text { Employment } \\
\text { status }\end{array}$ & $\begin{array}{l}\text { Total } \\
\text { sample } \\
(N)\end{array}$ & $\begin{array}{l}\text { Full } \\
\text { civil } \\
\left(n_{1}\right)\end{array}$ & $\begin{array}{l}\text { Full } \\
\text { electrical } \\
\left(n_{2}\right)\end{array}$ & $\begin{array}{l}\text { Full } \\
\text { mechanical } \\
\left(n_{3}\right)\end{array}$ & $\begin{array}{l}\text { Partial } \\
\text { civil } \\
\left(n_{4}\right)\end{array}$ & $\begin{array}{l}\text { Partial } \\
\text { electrical } \\
\left(n_{5}\right)\end{array}$ & $\begin{array}{l}\text { Partial } \\
\text { mechanical } \\
\left(n_{6}\right)\end{array}$ \\
\hline Working & 115 & 18 & 22 & 20 & 12 & 20 & 23 \\
\hline $\begin{array}{l}\text { Not working, } \\
\text { actively seeking new } \\
\text { opportunities }\end{array}$ & 17 & 2 & 0 & 3 & 7 & 2 & 3 \\
\hline $\begin{array}{l}\text { Not working, } \\
\text { not seeking } \\
\text { opportunities }\end{array}$ & 5 & 0 & 0 & 4 & 1 & 0 & 0 \\
\hline
\end{tabular}

As indicated in Table 2, majority of the participants were employed $(N=115)$ and the distribution in this sense appeared to be homogeneous in different EMI types. On the other hand, those who were unemployed and seeking new opportunities were relatively higher in the partial EMI civil engineering academic subject, and those who were unemployed but were not seeking new opportunities were mostly seen in the full EMI mechanical engineering academic subject. Due to the limited sample size and having all categorical variables, McFadden's Pseudo $\mathrm{R}^{2}$ was used to investigate the effect size of the findings. The asymmetrical distribution into the three-employment status might therefore point out the low effect size $\left(\mathrm{R}^{2}=.17, \sigma=.48\right)$. To determine if certain EMI subject types could help predict the employment status, Proportional Odds Logistic Regression was conducted as indicated in Table 3.

Table 3. Proportional Odds Logistic Regression for EMI Subject Type and Employment Status

\begin{tabular}{lllllll}
\hline & Predictor & B & SE $\boldsymbol{\beta}$ & $\begin{array}{l}\text { Wald's } \\
\boldsymbol{\chi 2}\end{array}$ & Df & $\boldsymbol{P}$ \\
\hline Threshold & $\begin{array}{l}\text { [Status = Not working, actively seeking } \\
\text { new opportunities] }\end{array}$ & -2.339 & .620 & 14.248 & 1 & .000 \\
& $\begin{array}{l}\text { [Status = Not working, not seeking new } \\
\text { opportunities] }\end{array}$ & -2.002 & .605 & 10.954 & 1 & .001 \\
\hline Location & [EMI_subject=full civil] & .165 & .952 & .030 & 1 & .862 \\
& [EMI_subject=full electrical] & 19.925 & .000 &. & 1 &. \\
& [EMI_subject=full mechanical] & -.841 & .753 & 1.246 & 1 & .264 \\
& [EMI_subject=partial civil] & -1.642 & .752 & 4.767 & 1 & .029 \\
& [EMI_subject=partial electrical] & .273 & .950 & .083 & 1 & .774 \\
& [EMI_subject=partial mechanical] & $0(\mathrm{a})$ &. &. & 0 &. \\
\hline
\end{tabular}

Link function: Logit.

a This parameter is set to zero because it is redundant.

Based on the findings in Table 3, it can be argued that EMI types of the participants (i.e., full vs. partial) could add to our understanding of the two employment status as "not working, actively seeking new opportunities" and "not working, not seeking new opportunities" ( $p$ $<.05)$. Furthermore, the results also indicated that full EMI electrical engineering, the partial EMI civil engineering, and the partial EMI mechanical engineering academic subjects were the subjects that explained the case in these two types of employment status. Figure 1 underpins these statistical findings. 


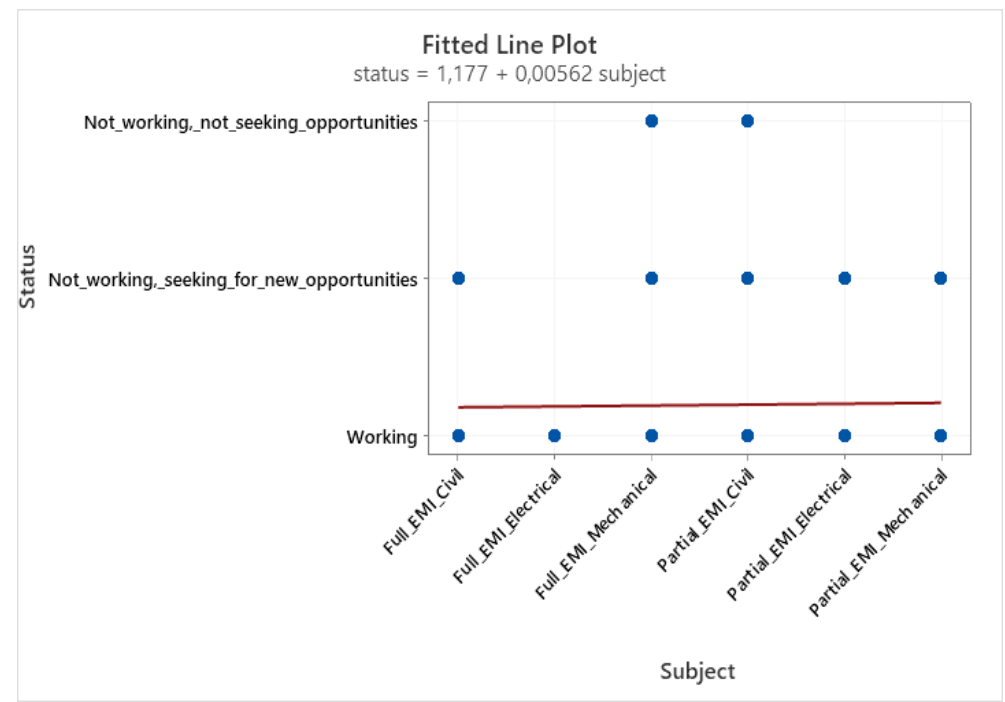

Figure 1. Fitted Line Plot for EMI Subject Type and Employment Status

Figure 1 illustrates the variation of these three EMI subjects when compared to the other subjects. The only two EMI subjects at which participants stated they were not working, or seeking opportunities were full EMI mechanical engineering and partial EMI civil engineering academic subjects. Besides, full EMI electrical engineering was the only subject at which all graduates were employed. As for the employed participants, all subjects seemed to be in line with one another and thus they did not help predict this third employment status.

\section{Income of the Participants}

A second concern of this study was if the participants' income could be predicted by the subjects they graduated from and their studying in partial or full EMI programmes. The survey item included unequal intervals that indicated the incomes of the participants as in Table 4. The financial data below relied on official declarations at the time of the data collection. The minimum wage in Turkey was then 2324 Turkish Liras (TL) while the hunger threshold was 2438 TL. Considering that some of the participants might be unmarried, 2961 Turkish Liras stood for the compulsory expenditure of the unmarried in Turkey. The last set of income variables was based on the poverty threshold, which was 7942 .

Table 4. Crosstabulation of the Income Status upon EMI Subject Types

\begin{tabular}{llllllll}
\hline $\begin{array}{l}\text { Income } \\
\text { (Turkish Liras) }\end{array}$ & $\begin{array}{l}\text { Total } \\
\text { sample } \\
(\boldsymbol{N})\end{array}$ & $\begin{array}{l}\text { Full } \\
\text { civil } \\
\left(\boldsymbol{n}_{\mathbf{1}}\right)\end{array}$ & $\begin{array}{l}\text { Full } \\
\text { electrical } \\
\left(\boldsymbol{n}_{\mathbf{2}}\right)\end{array}$ & $\begin{array}{l}\text { Full } \\
\text { mechanical } \\
\left(\boldsymbol{n}_{3}\right)\end{array}$ & $\begin{array}{l}\text { Partial } \\
\text { civil } \\
\left(\boldsymbol{n}_{\mathbf{4}}\right)\end{array}$ & $\begin{array}{l}\text { Partial } \\
\text { electrical } \\
\left(\boldsymbol{n}_{\mathbf{5}}\right)\end{array}$ & $\begin{array}{l}\text { Partial } \\
\text { mechanical } \\
\left(\boldsymbol{n}_{\mathbf{6}}\right)\end{array}$ \\
\hline Below 2324 & 8 & 0 & 0 & 0 & 0 & 0 & 8 \\
$\mathbf{2 . 3 2 4}$ to 2.438 & 2 & 2 & 0 & 0 & 0 & 0 & 0 \\
$\mathbf{2 4 3 8}$ to 2961 & 13 & 13 & 0 & 0 & 0 & 0 & 0 \\
$\mathbf{2 9 6 1}$ to 7942 & 81 & 3 & 22 & 27 & 20 & 9 & 0 \\
$\mathbf{7 9 4 2}$ or above & 31 & 0 & 0 & 0 & 0 & 11 & 18 \\
\hline
\end{tabular}

As seen in Table 4, only less than a quarter of the sample size indicated that their income was above the poverty threshold. Besides, more than a half of the total participants earned inbetween the compulsory expenditure of the unmarried and the poverty threshold. Based on the pseudo R-Square results, a medium effect size was observed in terms of the income distribution of the participants $\left(\mathrm{R}^{2}=.67, \sigma=1.18\right)$. Table 5 provides whether certain income intervals may be attributable to some specific EMI subjects. 
Table 5. Proportional Odds Logistic Regression for EMI Subject Type and Income Status

\begin{tabular}{|c|c|c|c|c|c|c|}
\hline & Predictor & $\boldsymbol{\beta}$ & SE $\beta$ & $\begin{array}{l}\text { Wald's } \\
\chi^{2}\end{array}$ & df & $p$ \\
\hline \multirow[t]{5}{*}{ Threshold } & {$[$ Income $=2.324 \mathrm{TL}-2.438 \mathrm{TL}]$} & -41.353 & 117.365 & .124 & 1 & .725 \\
\hline & $[$ Income $=2324$ (minimum wage $)]$ & -40.542 & 117.364 & .119 & 1 & .730 \\
\hline & [Income $=2438$ to 2961$]$ & -37.422 & 117.361 & .102 & 1 & .750 \\
\hline & [Income $=2961$ to 7942$]$ & -12.315 & 74.555 & .027 & 1 & .869 \\
\hline & {$[$ Income $=7942$ or above $]$} & .811 & .425 & 3.642 & 1 & .056 \\
\hline \multirow[t]{6}{*}{ Location } & [EMI_subject=full civil] & -39.156 & 117.363 & .111 & 1 & .739 \\
\hline & [EMI_subject=full electrical] & -24.922 & 119.425 & .044 & 1 & .835 \\
\hline & [EMI_subject=full mechanical] & -24.922 & 114.337 & .048 & 1 & .827 \\
\hline & [EMI_subject=partial civil] & -24.922 & 122.085 & .042 & 1 & .838 \\
\hline & [EMI_subject=partial electrical] & -11.947 & 74.556 & .026 & 1 & .873 \\
\hline & [EMI_subject=partial mechanical] & 0 (a) & & & 0 & \\
\hline
\end{tabular}

Link function: Logit.

a This parameter is set to zero because it is redundant.

Based on the information in Table 5, none of the income sets could be associated with a certain EMI subject. Still, those who earned higher than the poverty threshold were barely above the significance level $(\mathrm{p}=.056)$. Referring to the cross-tabulation in Table 5 as well as Figure 2, it is seen that partial EMI electrical engineering and partial EMI mechanical engineering academic subjects were the only two subjects whose participants earned at this level. Surprisingly, the rest of the participants from the latter subject earned less than the minimum wage. In contrast, the remaining samples of the partial EMI electrical engineering gathered all in the closest threshold set. Figure 2 is the illustration of the regression in the income according to the EMI subjects.

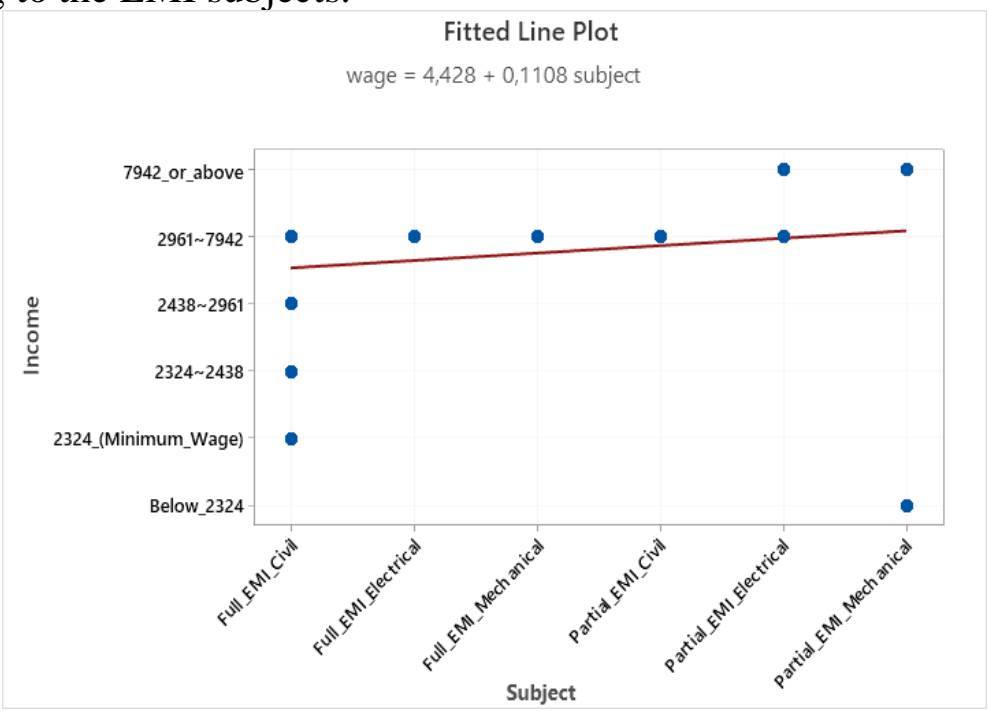

Figure 2. Fitted Line Plot for EMI Subject Type and Income

It is apparent in Figure 2 that the most diversely distributed EMI type was full EMI civil engineering. On the contrary, full EMI electrical engineering, full EMI mechanical engineering, and partial EMI civil engineering academic subjects were clustered within the same income level. Despite partial EMI electrical and partial EMI mechanical academic subjects being the only two subjects at which participants could earn 7942 Turkish Liras or above, the rest of the participants in the latter subject were accumulated in the extreme edge of the income scale, namely "Below 2324". Three participants from this subject previously stated that they were unemployed and seeking a new job. Even if they were considered to be 
earning less than the minimum wage, there still remained to be at least five more partial EMI mechanical engineering graduates.

\section{Attaining a Division-related Job}

It is common knowledge that not all the engineering graduates in Turkey work in a job related to their profession. Therefore, the participants were directed a third question with a view to learning whether their job was relevant to the division they graduated from (e.g., if they worked in a field related with engineering in some way or another). Although the coefficient of determination showed insignificant predictors $\left(\mathrm{R}^{2}=.08, \sigma=1.25\right)$, the results were remarkable in especially three specific academic subjects. Table 6 indicates the distribution in this respect according to the subjects of the participants.

Table 6. Crosstabulation of Working in a Division-related Job upon EMI Subject Types

\begin{tabular}{llllllll}
\hline $\begin{array}{l}\text { A division- } \\
\text { related job }\end{array}$ & $\begin{array}{l}\text { Total } \\
\text { sample } \\
(\boldsymbol{N})\end{array}$ & $\begin{array}{l}\text { Full } \\
\text { civil } \\
\left(\boldsymbol{n}_{\mathbf{1}}\right)\end{array}$ & $\begin{array}{l}\text { Full } \\
\text { electrical } \\
\left(\boldsymbol{n}_{\mathbf{2}}\right)\end{array}$ & $\begin{array}{l}\text { Full } \\
\text { mechanical } \\
\left(\boldsymbol{n}_{\mathbf{3}}\right)\end{array}$ & $\begin{array}{l}\text { Partial } \\
\text { civil } \\
\left(\boldsymbol{n}_{\mathbf{4}}\right)\end{array}$ & $\begin{array}{l}\text { Partial } \\
\text { electrical } \\
\left(\boldsymbol{n}_{\mathbf{5}}\right)\end{array}$ & $\begin{array}{l}\text { Partial } \\
\text { mechanical } \\
\left(\boldsymbol{n}_{\mathbf{6}}\right)\end{array}$ \\
\hline Yes & 117 & 18 & 20 & 22 & 14 & 21 & 22 \\
No & 20 & 2 & 2 & 5 & 6 & 1 & 4 \\
\hline
\end{tabular}

The descriptive findings in Table 6 indicated that approximately six seventh of the EMI engineering graduates worked in a division-related job. The graduates of partial EMI electrical engineering had proportionally better opportunities of finding a job related to engineering. On the contrary, those who graduated from partial EMI civil engineering had the weakest probability, which stood for almost a half of the partial civil engineering sample. Furthermore, mechanical engineering seemed to offer statistically the least division-related job opportunities among full EMI subjects. When comparing the EMI types, full EMI subjects had slightly better results with a total of 60 graduates who responded that they worked in a division-related job while it was 57 in partial EMI programmed. Based on the participants' responses, Table 7 indicates if different EMI subjects may predict working in a divisionrelated job.

Table 7. Proportional Odds Logistic Regression for EMI Subject Type and Working in a Division-related Job

$\begin{array}{llllll}\text { Predictor } & \beta & \text { SE } \beta & \chi^{2} & \text { Wald's } & \text { df }\end{array}$

\begin{tabular}{lllllll}
\hline Threshold & [Division_related = No] & -1.705 & .544 & 9.836 & 1 & .002 \\
\hline Location & [EMI_subject=full civil] & .492 & .923 & .285 & 1 & .593 \\
& [EMI_subject=full electrical] & .598 & .919 & .423 & 1 & .516 \\
& [EMI_subject=full mechanical] & -.223 & .735 & .092 & 1 & .762 \\
& [EMI_subject=partial civil] & -.857 & .730 & 1.378 & 1 & .240 \\
& [EMI_subject=partial electrical] & 1.340 & 1.159 & 1.336 & 1 & .248 \\
& [EMI_subject=partial mechanical] & $0(\mathrm{a})$ &. &. & 0 &. \\
\hline
\end{tabular}

Link function: Logit.

a This parameter is set to zero because it is redundant.

Table 7 demonstrated the existence of Type II error in the partial EMI civil engineering ( $\beta=-$ $.857)$ and full EMI mechanical engineering $(\beta=-.223)$. Therefore, the null hypothesis failed to be rejected. The statistical indications of the partial EMI mechanical engineering were yet another subject which had redundant scores as for having four respondents not working in a division-related job. Due mostly to these three EMI subjects, it could be argued that working 
in a division-related job can well be predicted by the academic subject one graduated from.

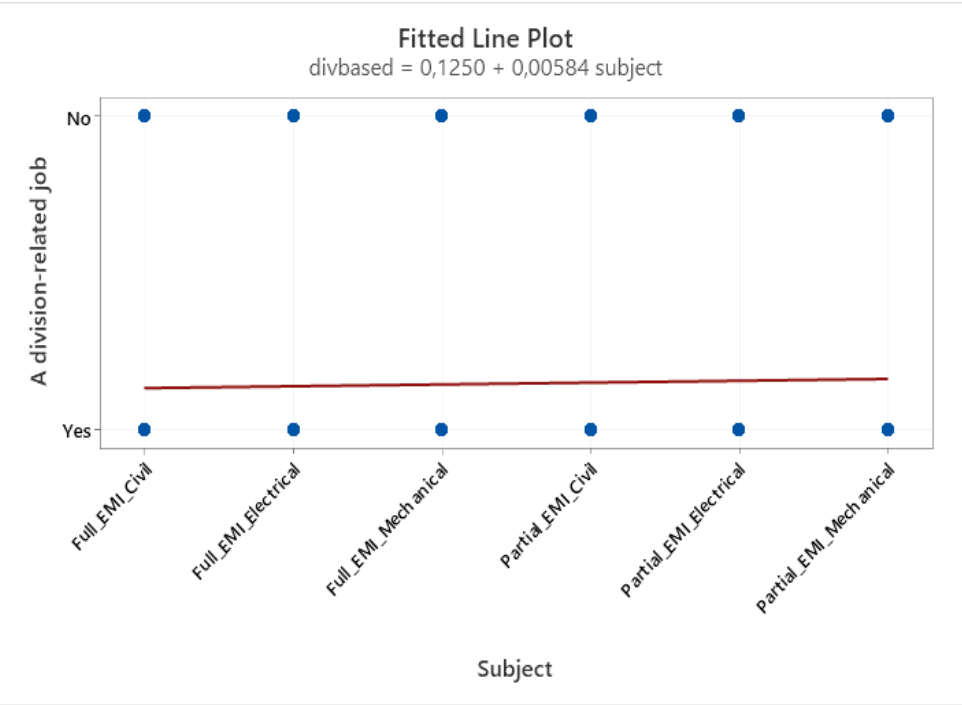

Figure 3. Fitted Line Plot for EMI Subject Type and Working in a Division-related Job

All in all, there were participants from all six EMI subjects who did not work in a divisionrelated job as seen in Figure 3. However, those who worked in a division-related job outnumbered them, hence constituting a weak effect size. Still, the three subjects mentioned above constituted less promising EMI programmes in terms of acquiring a division-related job.

\section{Acquiring a Subject-related Job}

Finding a subject-related job, likewise, might also be quite challenging for the students who graduated from engineering programmes in Turkey. Therefore, it was of the interest to investigate whether the variation in the EMI subjects predicted working in an academic subject-related job. Table 8 reflects the participants' variance accordingly.

Table 8. Crosstabulation of Working in a Subject-related Job upon EMI Subject Types

\begin{tabular}{llllllll}
\hline $\begin{array}{l}\text { A subject- } \\
\text { related job }\end{array}$ & $\begin{array}{l}\text { Total } \\
\text { sample } \\
(\boldsymbol{N})\end{array}$ & $\begin{array}{l}\text { Full } \\
\text { civil } \\
\left(\boldsymbol{n}_{\mathbf{1}}\right)\end{array}$ & $\begin{array}{l}\text { Full } \\
\text { electrical } \\
\left(\boldsymbol{n}_{\mathbf{2}}\right)\end{array}$ & $\begin{array}{l}\text { Full } \\
\text { mechanical } \\
\left(\boldsymbol{n}_{\mathbf{3}}\right)\end{array}$ & $\begin{array}{l}\text { Partial } \\
\text { civil } \\
\left(\boldsymbol{n}_{\mathbf{4}}\right)\end{array}$ & $\begin{array}{l}\text { Partial } \\
\text { electrical } \\
\left(\boldsymbol{n}_{\mathbf{5}}\right)\end{array}$ & $\begin{array}{l}\text { Partial } \\
\text { mechanical } \\
\left(\boldsymbol{n}_{\mathbf{6}}\right)\end{array}$ \\
\hline Yes & 117 & 18 & 19 & 20 & 13 & 12 & 19 \\
No & 20 & 2 & 3 & 7 & 7 & 10 & 7 \\
\hline
\end{tabular}

The overall proportion of those who did not work in a subject-related job to those who work in one was the same as given in the division-related job. However, the number of the participants who did not work in line with their subject professions were obviously higher. With a ratio of $45 \%$ of the participants not performing the profession that they were trained; the most heterogeneous variation here came from partial EMI electrical engineering. Partial EMI civil, partial EMI mechanical, and full EMI mechanical engineering academic subjects were respectively the ones at which less participants could find a subject-related job. As seen in the previous section, as few as $10 \%$ of full EMI civil engineering graduates worked in an unrelated job. Table 9 reveals if different EMI subjects can help predict these variations in the descriptive statistics. 
Table 9. Proportional Odds Logistic Regression for EMI Subject Type and Working in a Subject-related Job

\begin{tabular}{lllllll}
\hline & Predictor & $\boldsymbol{\beta}$ & SE $\boldsymbol{\beta}$ & $\begin{array}{l}\text { Wald's } \\
\boldsymbol{2}\end{array}$ & $\mathbf{d f}$ & $\boldsymbol{p}$ \\
\hline Threshold & [Subject_related = No] & -.999 & .442 & 5.100 & 1 & .024 \\
\hline Location & [EMI_subject=full civil] & 1.199 & .867 & 1.913 & 1 & .167 \\
& [EMI_subject=full electrical] & .847 & .763 & 1.235 & 1 & .266 \\
& [EMI_subject=full mechanical] & .051 & .623 & .007 & 1 & .934 \\
& [EMI_subject=partial civil] & -.379 & .644 & .347 & 1 & .556 \\
& [EMI_subject=partial electrical] & -1.181 & .615 & 3.681 & 1 & .055 \\
& [EMI_subject=partial mechanical] & $0(\mathrm{a})$ &. &. & 0 &. \\
\hline
\end{tabular}

Link function: Logit.

a This parameter is set to zero because it is redundant.

There seemed to be a Type II error in partial EMI engineering once again. To our surprise, the probability in partial EMI electrical engineering surpassed all other subjects $(\beta=-.181)$. Therefore, a comparison of Table 6 and Table 8 indicated that almost all the graduates of this subject worked as engineers; however, nearly half of them did not work as electrical engineers. Oppositely, the statistics of its full EMI counterpart was balanced in offering both division-related and subject-related jobs. From a broader perspective, the EMI subjects predicted whether a participant worked in a subject-related job $(\mathrm{p}<.05)$. The coefficient of variation represented a medium effect size $\left(\mathrm{R}^{2}=.45, \sigma=.47\right)$. Partial EMI programmes were overwhelmingly the determinant factors in this sense.

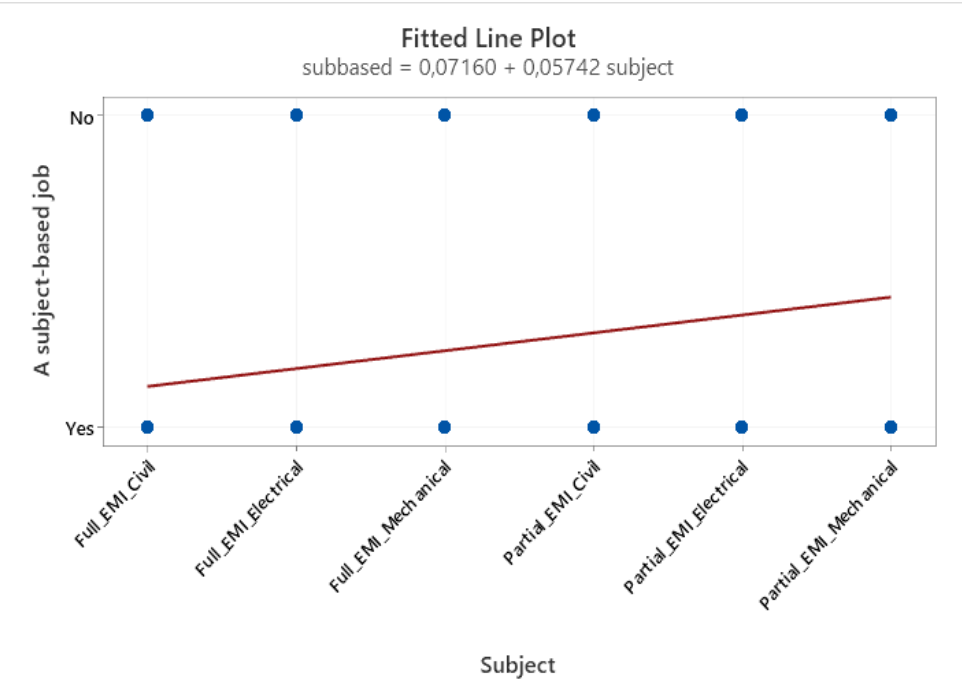

Figure 4. Fitted Line Plot for EMI Subject Type and Working in a Subject-related Job

The fitted line plot in Figure 4 outlined an upward tendency mostly in partial EMI subjects. It was also evident that full EMI civil engineering graduates adhered to their profession more than in any other programme. The data on having a division-related job justified this fact as well. Like in having a division-related job, all subjects included participants working in an unrelated job to their subjects.

\section{Duration of Seeking a Job}

The time spent on seeking a job was investigated through a final survey item. The motivation behind this question was intending to shed light on subject-related variance in 
finding a job as well as on any influence of the EMI types. The participants were provided with unequal duration intervals as given in Table 10:

Table 10. Crosstabulation of Duration of Seeking a Job upon EMI Subject Types

\begin{tabular}{llllllll}
\hline Duration & $\begin{array}{l}\text { Total } \\
\text { sample } \\
(\boldsymbol{N})\end{array}$ & $\begin{array}{l}\text { Full } \\
\text { civil } \\
\left(\boldsymbol{n}_{\mathbf{1}}\right)\end{array}$ & $\begin{array}{l}\text { Full } \\
\text { electrical } \\
\left(\boldsymbol{n}_{\mathbf{2}}\right)\end{array}$ & $\begin{array}{l}\text { Full } \\
\text { mechanical } \\
\left(\boldsymbol{n}_{\mathbf{3}}\right)\end{array}$ & $\begin{array}{l}\text { Partial } \\
\text { civil } \\
\left(\boldsymbol{n}_{\mathbf{4}}\right)\end{array}$ & $\begin{array}{l}\text { Partial } \\
\text { electrical } \\
\left(\boldsymbol{n}_{5}\right)\end{array}$ & $\begin{array}{l}\text { Partial } \\
\text { mechanical } \\
\left(\boldsymbol{n}_{\mathbf{6}}\right)\end{array}$ \\
\hline 0-3 months & 70 & 15 & 14 & 11 & 9 & 13 & 8 \\
3-6 months & 32 & 2 & 5 & 6 & 5 & 3 & 11 \\
6-12 months & 19 & 3 & 1 & 6 & 2 & 3 & 4 \\
1-2 years & 13 & 0 & 2 & 4 & 2 & 3 & 2 \\
Over 2 years & 3 & 0 & 0 & 0 & 2 & 0 & 1 \\
\hline
\end{tabular}

Table 10 showed that approximately half of the participants found a job within the first three months after graduation. Full EMI subjects apparently deviated in a positive manner from partial EMI subjects. Around 15\% of all partial EMI samples selected either of the options above a year, whereas it was less than $9 \%$ in full EMI programmes. Moreover, none of the full EMI civil engineering graduates waited longer than a year. For a more precise approach, Table 11 specifies the influence of different EMI subjects and types over the duration of job hunt.

Table 11. Proportional Odds Logistic Regression for EMI Subject Type and Duration of Seeking a Job

\begin{tabular}{lllllll}
\hline & Predictor & $\boldsymbol{\beta}$ & SE $\boldsymbol{\beta}$ & $\begin{array}{l}\text { Wald's } \\
\boldsymbol{\chi 2}\end{array}$ & df & $\boldsymbol{p}$ \\
\hline Threshold & [Duration = 0-3 months] & -.664 & .369 & 3.247 & 1 & .072 \\
& [Duration = 1-2 years] & -.244 & .365 & .447 & 1 & .504 \\
& [Duration = 3-6 months] & 1.041 & .380 & 7.486 & 1 & .006 \\
& [Duration = 6-12 months] & 3.209 & .650 & 24.373 & 1 & .000 \\
\hline Location & [EMI_subject=full civil] & -1.598 & .609 & 6.891 & 1 & .009 \\
& [EMI_subject=full electrical] & -1.279 & .565 & 5.121 & 1 & .024 \\
& [EMI_subject=full mechanical] & -.345 & .499 & .478 & 1 & .489 \\
& [EMI_subject=partial civil] & -.381 & .542 & .496 & 1 & .481 \\
& [EMI_subject=partial electrical] & -1.055 & .552 & 3.661 & 1 & .056 \\
& [EMI_subject=partial mechanical] & $0($ a) &. &. & 0 &. \\
\hline
\end{tabular}

Link function: Logit.

a This parameter is set to zero because it is redundant.

As given in Table 11, the commonality of the Type II error in the variances of EMI subject signalled a regression in the duration of seeking a job. The case was more explicit in full EMI civil engineering and full EMI electrical engineering subjects ( $\mathrm{p}<.05)$. Partial EMI electrical engineering academic subject stood for the subject with the most significant correlation of the subject and the duration spent on seeking a job. Due to the rather heterogeneous accumulation of the samples into various duration intervals, the significance levels also altered. Still, the durations of 6-12 months and 3-6 months appeared to be better predicted by the independent variables of EMI subjects. Additionally, 0-3 months duration was barely above the significance threshold $(\mathrm{p}=.072)$. Similar to the previous survey item, the coefficient of variance in this item addressed to a medium effect size $\left(\mathrm{R}^{2}=.32, \sigma=1.09\right)$. In sum, the duration spent on seeking a job could be predicted considering different EMI subjects and types. 


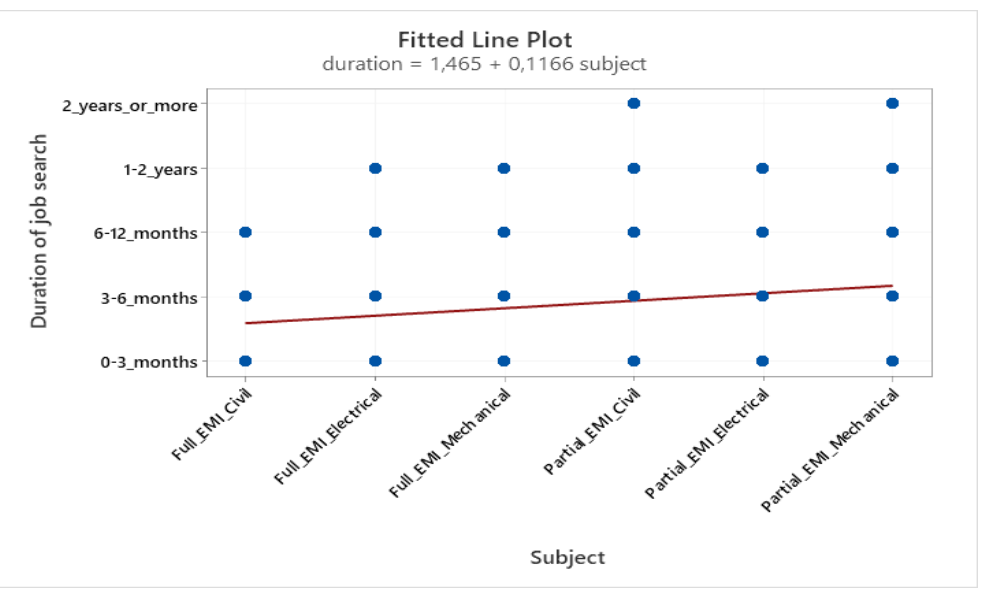

Figure 5. Fitted Line Plot for EMI Subject Type and Duration of Job Search

As visualised in Figure 5, the participants from all six EMI subjects were scattered widely within the first year of their job hunt. Only full EMI civil engineering was excluded over the first year; but there were only two EMI subjects, namely partial EMI civil engineering and partial EMI mechanical engineering academic subjects, at which graduates continued seeking a job even after two years. All in all, about $75 \%$ of the samples were employed in half a year after graduation.

\section{Conclusion and Discussion}

This study focused on the impact of EMI studies on the students' careers after graduation in various engineering academic subjects. Specifically, variation in different academic subjects as well as different implementation models of EMI have been explored. Our findings revealed, in terms of the employment status, that electrical engineering of both full and partial EMI programmes offered better conditions after graduation when compared to the other subjects. Although there was not a significant difference between the EMI types, none of the full EMI graduates of electrical engineering in this study were unemployed. This might be due to some conditions related with the job market, which is outside the focus of this study. Besides, unemployment was quite common in the mechanical engineering academic subject. Moreover, there was a balance between the full and partial EMI graduates of mechanical engineering programmes in terms of seeking a job. However, it was also quite common among the full EMI mechanical engineering graduates to be unemployed on their own will (i.e. they had stopped seeking a job). Although employment in the full EMI civil engineering was at a satisfactory level, it was vice versa in the partial EMI programme with the least? unemployment rate among all engineering graduates. A significant proportion of the graduates were seeking a job. Assuming that most civil engineers work freelance or selfemployed, those who were not economically self-sufficient to do so might have been a trigger factor of the unemployment in this subject. The mixed results in terms of employment opportunities in previous studies (Altay, 2020; Hu, Li, \& Lei, 2014) reinforce our findings as we have observed a wide range of variety in our findings in different departments.

Although unemployment was relatively more common among partial EMI subjects, the income status contradicted this finding. There were only the two partial EMI subjects, namely electrical engineering and mechanical engineering, at which graduates could earn above the poverty threshold. However, it was an all-or-none case among the remaining group as a considerable ratio of the graduates in this group earned below the minimum wage, aside from 
the unemployed ones. Excluding partial EMI mechanical engineering graduates, more than a half of the participants could earn between the compulsory expenditure of the unmarried in Turkey and the poverty threshold. Considering that engineers had the reputation of earning beyond most other lines of business, it might be a hypothetical, if not disputable, overgeneralization (Taylor, 2007). Engineering graduates from American institutions of higher education expect or get a similar (above average) salary (Taylor, 2007) similar to their Turkish EMI counterparts, which was also observed in different parts of the world such as China (Mok et al., 2016).

When the issue was working in a division-related job, electrical engineers seemed to be on the safe side. Mechanical engineers, on the other hand, were open for other business fields. This could be a result of the broad-spectrum nature of the content knowledge in this profession (Mullisen, 1999). Although 85\% of the participants worked as engineers, not that many of them were lucky enough to or opted for acquiring a job related to their subject profession. That is to say, there was a remarkable diversity in the field of engineering, and as a consequence of this fact, the graduates could well be employed in other related or unrelated professions, but still worked as engineers. This was especially true among the graduates of partial EMI electrical engineering. The statistical variation between working in a divisionrelated job and working in a subject-related job might also mean that the graduates welcomed a position as long as they work as an engineer, yet they were not much enthusiastic in any other profession than engineering considering the job market and opportunities (Mok, et al., 2016; Tantekin-Ersolmaz, 2006).

Regardless of the engineering types, partial EMI subjects of all sorts had worse statistics in terms of the duration of finding a job, which was also reported in some other studies (Tantekin-Ersolmaz, 2006). Amongst the full EMI programmes, it might take a longer time for mechanical engineers to get employed. Based on our findings, it was uncommon for electrical engineers to seek a job longer than two years, regardless of graduating from a partial or a full EMI programme. This might imply an industrial demand for this subject, but the case might also be a result of the flexibility and generalizability of the content knowledge of the subject. Civil engineering, chiefly the full EMI programme, also bears similar indications. The very same assumption of most civil engineers' working freelance or self-employed might explain the reduced duration on seeking a job.

All in all, in this study, we have portrayed that different EMI academic subjects have different prospects in the job market, and we could also observe variety in the same academic subject that employed a different EMI model. These results, when read together, can shed light onto the career opportunities in various EMI engineering programmes in Turkey and contribute to the limited scientific knowledge we have about the contribution of our higher education institutions to the career prospects of their graduates.

\section{Limitations}

It is plausible that a number of limitations might have influenced the results obtained. To begin with, the data came from the graduates of two universities and may not be generalized to all other EMI programmes both nationally and globally. Considering that the participants were from only three engineering academic subjects, it may have some drawbacks in terms of reflecting the overall framework in engineering. A final restriction might be the lack of qualitative data which might have provided a better illustration of the career prospects of the engineering students in our study. 


\section{Suggestions for further research}

In line with the limitations above, further research can be conducted aiming at including more universities and various engineering subjects. These studies may nourish the findings with the triangulated data concerning the effectiveness of the programmes of the graduates. The qualitative findings can better scaffold the implications of EMI programmes in engineering graduates' job prospects.

\section{References}

Altay, M. (2020). The implications of EMI education for graduates' employment conditions. Kocaeli University Institute of Social Sciences Journal, 40(2), 109-120. https://doi.org/10.35343/kosbed.810502

Altay, M., \& Ercin, N. (2020). Uncovering the reflections of English medium instruction in engineering graduates' career. Sakarya University Journal of Education, 10(3), 577 588. https://doi.org/577-588. 10.19126/suje.760104

Altay, M., Soruc, A., Yuksel, D., Curle, S. (under review). Investigating academic achievement of English Medium Instruction courses in Turkey: The influence of English proficiency, first language medium, academic subject. Studies in Second Language Learning and Teaching.

Björkman, B. (2008). 'So where we are?' Spoken lingua franca English at a technical university in Sweden. English Today, 24(2), 35-41.

Cohen, J. (1988). Statistical power analysis for the behavioral sciences (2nd ed.). Hillsdale, NJ: Lawrence Earlbaum Associates.

Curle, S., Yuksel, D., Soruc, A., \& Altay, M. (2020). Predictors of English medium instruction academic success: English proficiency versus first language medium. System, 95. https://doi.org/10.1016/j.system.2020.102378

Dafouz, E., (2018) English-medium instruction and teacher education programmes in higher education: ideological forces and imagined identities at work. International Journal of Bilingual Education and Bilingualism, 21(5), 540552.

Doiz, A., Lasagabaster, D., \& Sierra, J. M. (2012). English-medium instruction at universities: Global challenges. https://doi.org/10.1093/elt/cct045

Dörnyei, Z. (2007). Research methods in applied linguistics. New York: Oxford University Press.

Fang, F. (2018). Review of English as a medium of instruction in Chinese universities today: Current trends and future directions: New language policies to promote multilingualism and language support for EMI will be needed in Chinese tertiary contexts. English Today, 34(1), 32-37. doi:10.1017/S0266078417000360

Galloway, N. (2017). How effective is English as a medium of instruction (EMI)? Retrieved April 20, 2020 from British Council: https://www.britishcouncil.org/voices-magazinehow-effective-english-medium-instruction-emi.

Galloway, N., J. Kriukow, and T. Numajiri. 2017. Internationalisation, Higher Education and the Growing Demand for English: an Investigation into the English Medium of Instruction (EMI) Movement in China and Japan. London: British Council.

Graddol, D. (2006). English next. Oxford: British Council.

Gil, J. (2010). The double danger of English as a global language. English Today, 26(1), 5156.

Hu, G., Li, L., \& Lei, J. (2014). English-medium instruction at a Chinese University: Rhetoric and reality. Language Policy, 13, 21-40. https://doi.org/10.1007/s10993-0139298-3 
Huang, B. (2011). Economic development and the growing importance of the English language in Guangxi. In A. Feng (Ed.), English Language Education Across Greater China. London: Multilingual Matters Inc.

Irvine, A., Pecorari, D., Shaw, P., \& Malmström, H. (2011). English for Academic Purposes at Swedish universities: Teachers' objectives and practices. Ibérica, 22, 5578.

Kurkgöz, Y. (2005). Motivation and student perception of studying in an English-medium university. Journal of Language and Linguistic Studies, 1(1), 101-123.

Kırkgöz, Y. (2014). Students' perceptions of English language versus Turkish language used as the medium of instruction in higher education in Turkey. Turkish Studies, 9(12), $443-459$.

Macaro, E. (2018). English medium instruction. Oxford: Oxford University Press.

Mok, K.H., Wen, Z., \& Dale, R. (2016). Employability and mobility in the valorisation of higher education qualifications: the experiences and reflections of Chinese students and graduates. Journal of Higher Education Policy and Management, 38(3), 264-281.

Mullisen, R.S. (1999). A mechanical engineering programme categorized into curricular threads. International Journal of Mechanical Engineering Education, 27(3), 230-234.

O'Dowd, R. (2015). The training and accreditation of teachers for English-medium instruction: a survey of European universities. Leon: Universidad de León.

Oz, H. H. (2005). Accreditation processes in Turkish higher education. Higher Education in Europe, 30(3-4). 335-344.

Nguyen H.T., Walkinshaw I., \& Pham H.H. (2017). EMI programs in a Vietnamese university: language, pedagogy and policy issues. In: Fenton-Smith B., Humphreys P., Walkinshaw I. (Eds) English medium instruction in higher education in Asia-Pacific. Springer, Cham.

Peng, C.-Y., J., Lee, K. L., \& Ingersoll, G. M. (2002). An introduction to logistic regression analysis and reporting. The Journal of Educational Research, 96, 3-14.

Sert, N. (2008). The language of instruction dilemma in the Turkish context. System 36, 156171.

Soruç, A., Dinler, A., \& Griffiths, C. (2018). Listening comprehension strategies of EMI students in Turkey. In Y. Kırkgöz \& K. Dikilitaş (Eds.), Key issues in English for specific purposes in higher education (pp. 265-287). Springer, Cham. https://doi.org/10.1007/978-3-319-70214-8_15

Soruç, A., \& Griffiths, C. (2018). English as a medium of instruction: students' strategies. ELT Journal, 72(1), 38-48. https://doi.org/10.1093/elt/ccx017

Tantekin-Ersolmaz, S. B., Ekinci, E. \& Saglamer, G. (2006). Engineering education and practice in Turkey. IEEE Technology and Society Magazine, 25 (2), 26-35.

Taylor, D. (2007). Employment preferences and salary expectations of students in science and engineering. BioScience, 57(2), 175-185.

Wächter, B., \& Maiworm, F. (2014). English-taught programmes in European higher education: the state of play in 2014. Bonn: Lemmens Medien.

Yang, J. (2006). Learners and users of English in China. English Today, 22(2). 3-10.

Zhang, Z. (2017). English-medium instruction policies in China: internationalisation of higher education. Journal of Multilingual and Multicultural Development, 39(6), 542555. 


\section{Appendix}

The descriptive survey includes the following items:

1) What is your current employment status?

A) Working

$B$ ) B) Not working, actively seeking new opportunities

C) Not working, not seeking opportunities

2) Which of the following reflects your income status?
A) Below 2324
B) 2324 to 2438
C) 2438 to 2961
D) 2961 to 7942
E) 7942 or above
3) Do you work in a division-related job?
A) Yes
B) $\mathrm{No}$
4) Do you work in a subject-related job?
A) Yes
B) $\mathrm{No}$

5) How long did it take you to find a job?
A) 0-3 months
B) 3-6 months
C) 6-12 months
D) 1-2 years
E) Over 2 years 